\title{
Functional lateralization of lexical stress representation: a systematic review of patient data
}

\author{
Katja Häuser ${ }^{1,2}$ and Frank Domahs ${ }^{3 *}$ \\ 1 Department for Communication Sciences and Disorders, McGill University, Montreal, QC, Canada \\ ${ }^{2}$ Centre for Research on Brain, Language and Music, McGill University, Montreal, OC, Canada \\ ${ }^{3}$ Institute of Germanic Linguistics, Philipps-University Marburg, Marburg, Germany
}

\section{Edited by:}

Richard Wiese, Philipps-Universität

Marburg, Germany

Reviewed by:

Marie Klopfenstein, Southern Illinois

University Edwardsville, USA

Christina Samuelsson, Linköping

University, Sweden

${ }^{*}$ Correspondence:

Frank Domahs, Institute of

Germanic Linguistics,

Philipps-University Marburg,

Wilhelm-Röpke-Str., 6a,

D-35032 Marburg, Germany

e-mail:domahs@uni-marburg.de
According to the functional lateralization hypothesis (FLH) the lateralization of speech prosody depends both on its function (linguistic $=$ left, emotional $=$ right) and on the size of the units it operates on (small = left, large = right). In consequence, according to the FLH, lexical stress should be processed by the left (language-dominant) hemisphere, given its linguistic function and small unit size. We performed an exhaustive search for case studies of patients with acquired dysprosody due to unilateral brain damage. In contrast to previous reviews we only regarded dysprosody at the lexical level (excluding phrasal stress). Moreover, we focused on the representational stage of lexical stress processing, excluding more peripheral perceptual or motor deficits. Applying these criteria, we included nine studies reporting on 11 patients. All of these patients showed representational deficits in word stress processing following a lesion in their language-dominant hemisphere. In 9 out of 11 patients, it was the left hemisphere which was affected. This is a much more consistent pattern as found in previous reviews, in which less rigorous inclusion criteria may have blurred the pattern of results. We conclude that the representation of lexical stress crucially relies on the functioning of the language-dominant (mostly left) hemisphere.

Keywords: word stress, representational knowledge, left hemisphere, right hemisphere, acquired disorders of language, dysprosody

\section{INTRODUCTION}

According to the functional lateralization hypothesis (FLH; Van Lancker, 1980; Van Lancker Sidtis et al., 2006) the lateralization of speech prosody depends both on its function and the size of the linguistic unit it operates on. Processing of prosody with an emotional function is assumed to be accomplished by the right hemisphere, whereas prosody with a linguistic function should be processed by the left or language-dominant hemisphere. Moreover, the right hemisphere is assumed to operate on larger scale linguistic units such as phrases or sentences, while small units such as syllables should be processed by the left (language dominant) hemisphere. In consequence, according to the FLH, lexical stress should be processed by the left (languagedominant) hemisphere, given its linguistic function and small unit size (Van Lancker, 1980; Wong, 2002).

One relevant source of evidence for the FLH are neuropsychological case studies. If lexical stress processing is found to be impaired in subjects with unilateral brain damage, this would provide insights into the neural substrates that are necessarily involved in the processing of this aspect of prosody. However, so far such studies have yielded mixed results with respect to the FLH, and different reviews have arrived at conflicting results (Baum and Pell, 1999; Wong, 2002). Whereas the authors in one review concluded that there is sufficient evidence in favor of a consistent involvement of left hemisphere substrates in lexical stress processing (Baum and Pell, 1999), another review found the results too inconclusive to fully support the hypothesis of functional lateralization (Wong, 2002). These contradicting conclusions can partly be attributed to diverging methods and interpretations of the results. For example, Wong (2002) stated that since not all reviewed studies consistently include an LHD, RHD, and normal control group, some results are impossible to evaluate against the hypothesis of functional lateralization. Another potential problem is the fact that most previous studies have intermixed tasks involving different stages of lexical stress processing (such as perception, representation, and production), although it seems implausible that these processing stages are accomplished by the same neural regions at all (for a review, see Zatorre and Gandour, 2008). This has possible consequences for lateralization according to the FLH and could also explain why previous reviews did not reach a consistent conclusion in this matter. Finally, existing reviews often included clinical case studies conducted in English, some of which have insufficiently distinguished the size of the linguistic units under consideration. In some studies, compound noun phrases (green 'house vs. 'greenhouse) have been investigated on the same level as noun/verb minimal pairs ('convict vs. con'vict). Such an approach is potentially problematic, since noun phrases have greater semantic and syntactic complexity than compound nouns or simplex nouns and verbs (Wasow, 1997). Consequently, 'green house is not minimally distinct from green 'house in regards to word stress alone. Crucially, they also differ in the size of linguistic units involved which has implications for the lateralization of processing according to the FLH. In sum, various reasons ranging from differing methodologies 
to contrasting interpretations could explain the rather mixed evidence that has been discussed with respect to the FLH so far.

The goal of the present study was to review existing case reports with respect to the functional lateralization of lexical stress. In contrast to previous reviews (Baum and Pell, 1999; Wong, 2002), we only considered clinical case studies that investigated prosody at a purely lexical level, thus excluding studies on noun phrase or compound noun stress processing. Moreover, we focused on the representational stage of lexical stress processing, excluding perceptional and articulatory deficits. Our aim was to evaluate evidence informative to the claim that lexical stress is represented in the language-dominant (i.e., mostly left) hemisphere.

\section{METHODS}

We conducted an exhaustive search on the data bases Google Scholar, PubMed, and Entrez, using the search terms lexical stress AND brain damage, lexical stress AND hemisphere, and lexical stress AND aphasia. We discarded all studies that did not focus on individuals with unilateral brain damage and/or did not investigate stress assignment at a purely lexical level (for example, studies on tone or phrase level stress). In addition, we excluded all studies in which prosodic impairments in speech production could also result from more peripheral perceptual or articulatory difficulties (e.g., cases of dysarthric or apraxic impairment). After the application of these exclusion criteria, 12 articles remained for analysis, reporting on 15 patients with representational impairments in lexical stress processing (meaning that these patients displayed impairments in stress assignment). We reviewed all 12 studies for hemispheric site of lesion and language-dominant hemisphere of the patient. If both types of information were missing and could not be inferred based on the information provided by the authors, the study and/or subject was excluded from further analysis, resulting in the exclusion of four studies/subjects (excluded studies: Lloyd, 1999; Howard and Smith, 2002; Janssen, 2003. excluded subject: DE in Black and Byng, 1986). An overview on all studies and patients included is provided in Table 1.

The languages spoken by the patients included in our analyses were English, German, and Italian-all languages with variable stress. This means that although in all three languages, word stress assignment shows some regularities (for an overview, see Van der Hulst, 1999), the assignment of stress to individual words cannot be inferred by phonemic or orthographic rules alone and thus requires activation of word-specific (i.e., lexical) phonological representations (Miceli and Caramazza, 1993). The word stress errors reported by the studies included in this review particularly affected words with infrequent or "irregular” stress patterns (Coltheart et al., 1983; Chiacchio et al., 1993; Miceli and Caramazza, 1993; Cappa et al., 1997; Rozzini et al., 1997; Galante et al., 2000; Laganaro et al., 2002; Janssen and Domahs, 2008), typically leading to shifts in stress assignment to the most frequent pattern ("over-regularisations", e.g., Marshall and Newcombe, 1973; Black and Byng, 1986; Cappa et al., 1997; Laganaro et al., 2002; Janssen and Domahs, 2008).

\section{RESULTS}

\section{CLASSIFICATION BASED ON HANDEDNESS}

This analysis is based on the fact that handedness is closely related to hemispheric dominance for language (e.g., Knecht et al., 2000). Out of the ten studies with 12 patients that remained in the pool (see Table 1), data on both the impaired hemisphere and the patient's handedness were available in eight cases. All of these eight patients presented with systematic errors in stress assignment following a lesion in their language-dominant hemisphere

Table 1 | Table of patients included in the review.

\begin{tabular}{|c|c|c|c|c|c|c|c|c|c|c|c|}
\hline Study & Patient & Hand & Hemisphere & Site & Syndrome & Fluency & Etiology & $\begin{array}{l}\text { Nam } \\
(\%)\end{array}$ & $\begin{array}{l}\text { Read } \\
(\%)\end{array}$ & $\begin{array}{c}\text { Repet } \\
(\%)\end{array}$ & $\begin{array}{l}\text { Lex. Dec. } \\
(\%)\end{array}$ \\
\hline Chiacchio et al., 1993 & $\mathrm{CA}$ & $\mathrm{R}$ & $\mathrm{LH}$ & $\mathrm{T}$ & $\begin{array}{l}\text { Surface dyslexia, } \\
\text { PPA }\end{array}$ & $\mathrm{FL}$ & DEG & & 30 & & \\
\hline Galante et al., 2000 & $\mathrm{RM}$ & $\mathrm{R}$ & $\mathrm{LH}$ & T, Ven & $\begin{array}{l}\text { Surface dyslexia, } \\
\text { PPA }\end{array}$ & $\mathrm{FL}$ & DEG & & 21 & & \\
\hline Laganaro et al., 2002 & MS & $L+R$ & $\mathrm{LH}$ & $x$ & Aphasia, Apraxia & NFL & CVA & 10 & 12 & 10 & 7 \\
\hline Rozzini et al., 1997 & $A C$ & $\mathrm{R}$ & $\mathrm{LH}$ & T, Ven & Surface dyslexia & $\mathrm{FL}$ & DEG & & 27 & & \\
\hline Janssen and Domahs, 2008 & HAT & $\mathrm{R}$ & $\mathrm{LH}, \mathrm{RH}$ & T, Sub & $\begin{array}{l}\text { Surface dyslexia, } \\
\text { PPA }\end{array}$ & $\mathrm{FL}$ & DEG & & 25 & 2 & \\
\hline \multirow[t]{2}{*}{ Marshall and Newcombe, 1973} & ST & $x$ & $\mathrm{LH}$ & $\mathrm{T}, \mathrm{P}$ & Surface dyslexia & $\mathrm{FL}$ & $\mathrm{OHI}$ & & xs & & \\
\hline & $\mathrm{JC}$ & $x$ & $\mathrm{LH}$ & $\mathrm{T}, \mathrm{P}$ & Surface dyslexia & $\mathrm{FL}$ & $\mathrm{OHI}$ & & $x$ & & \\
\hline Black and Byng, 1986 & $\mathrm{RW}$ & $x$ & $\mathrm{LH}$ & $\mathrm{T}, \mathrm{P}$ & Deep dyslexia & $\mathrm{FL}$ & $\mathrm{OHI}$ & & 3 & & \\
\hline Cappa et al., 1997 & GM & $\mathrm{R}$ & $\mathrm{LH}$ & $\mathrm{T}$ & Conduction aphasia & $\mathrm{FL}$ & $\mathrm{OHI}$ & 18 & 14 & & \\
\hline
\end{tabular}

Hand, reported handedness; Hemisphere, lesioned hemisphere; Site, site of lesion (if available); T, Temporal; Ven, Ventricle; P, Parietal; F, Frontal. Etiology: DEG, Degenerative; OHI, Open Head Injury; CVA, Cerebral Vascular Accident.

Tasks: nam, picture naming; read, reading; repet, repetition; lex. dec., lexical decision task performance is indicated in \% errors. x's indicate missing information. 
(which was the LH in seven patients and the RH in one patient), as inferred from handedness.

\section{CLASSIFICATION BASED ON LINGUISTIC IMPAIRMENT}

All 12 patients (including the four cases where handedness information was not available) showed major linguistic impairments, suggesting that they suffered from lesions in their languagedominant hemisphere. This yields a total of 12 out of 12 patients who showed representational deficits in word stress processing following a lesion in their language-dominant hemisphere. In 10 out of 12 patients, it was the left hemisphere which was affected.

\section{DISCUSSION}

The goal of this study was to review evidence from acquired language impairment regarding the functional lateralization hypothesis (FLH, Van Lancker, 1980; Van Lancker Sidtis et al., 2006), which states that function and size of a prosodic unit determine the cortical hemisphere it is processed in. Specifically, we were interested in the representation of lexical stress, which according to the FLH is a property of the left, language-dominant hemisphere. To this end, we reviewed clinical case studies that focused on brain-damaged patients with representational impairments in lexical stress assignment. Ten studies reporting on 12 cases remained for analysis after the application of all exclusion criteria. The results showed that in all of these patients, impairments in lexical stress assignment followed a lesion in the languagedominant hemisphere. In contrast to earlier reviews, which have arrived at mixed results, our data thus fully support the functional lateralization hypothesis.

The sample of studies that met our inclusion criteria was rather small, given that only few studies addressed the representation (rather than perception or articulation) of lexical stress. However, our rigorous and hypothesis-driven approach yielded a very clear pattern of results, in comparison to previous reviews that investigated speech prosody. In fact, a closer look at patients which were excluded from our analyses because they did not fulfill our criterion of a representational impairment (either because of a speechmotor deficit, e.g., dysarthria, or because of a non-specified deficit affecting lexical stress processing) revealed a much less consistent pattern: 82 of those patients had a left-hemisphere lesion, in comparison to 74 patients with right-hemisphere damage. Furthermore, 65 patients were reported to have lesions at the side of their dominant hand. Clearly, allowing for less precision in the nature of lexical dysprosody (as in previous reviews) would have led to a more impressive number of cases but to a blurred pattern of results. After all, it is highly plausible that perceptual and motor stages of lexical stress processing are subserved by bilateral brain areas whereas the more abstract linguistic representation of word prosody may reside in the language-dominant (left) hemisphere. This could explain the mixed evidence that earlier reviews yielded with respect to the FLH (Baum and Pell, 1999; Wong, 2002).

Our findings are consistent with evidence from dichotic listening showing that stress typicality effects (indicative of the representational stage of stress processing) only appeared in repetition and noun/verb-classification when stimuli were presented to the right ear/left hemisphere (Arciuli and Slowiaczek, 2007).
More generally, our findings are also consistent with previous studies (Baum and Pell, 1999) that have rejected a strict division of labor regarding the hemispheric representation of prosody. Even though our results support the notion that lexical stress is a property of the language-dominant hemisphere, it seems that any global "all-left" or "all-right" account with respect to the hemispheric lateralization of all prosodic functions is an oversimplification and fails to account for the data. In this context, it seems that to date the FLH is the most promising account put forward to describe the neural substrates of prosody, since it does not set up an all-or-none division for prosodic functions but allows for gradedness of prosodic representation, depending on their function and the size of the processing units involved. This claim is also substantiated by findings in neuro-imaging, which have demonstrated bilateral cortical activations for lexical stress processing (Aleman et al., 2005; Wildgruber et al., 2006; Klein et al., 2011; Domahs et al., 2013). Yet, it is the methodological strength of lesion studies to highlight the functional relevance of brain regions for cognitive functions (Rorden and Karnath, 2004).

In sum, based on the data at hand we conclude that the representation of lexical stress crucially relies on the functioning of the language-dominant (mostly left) hemisphere.

\section{ACKNOWLEDGMENTS}

This research was supported by a grant from the LOEWE initiative of excellence of the Hessian Ministry of Research and the Arts (project LingBas).

\section{REFERENCES}

Aleman, A., Formisano, E., Koppenhagen, H., Hagoort, P., de Haan, E. H., and Kahn, R. S. (2005). The functional neuroanatomy of metrical stress evaluation of perceived and imagined spoken words. Cereb. Cortex 15, 221-228. doi: 10.1093/cercor/bhh124

Arciuli, J., and Slowiaczek, L. M. (2007). The where and when of linguistic word-level prosody. Neuropsychologia 45, 2638-2642. doi: 10.1016/j.neuropsychologia.2007.03.010

Baum, S. R., and Pell, M. D. (1999). The neural bases of prosody: insights from lesion studies and neuroimaging. Aphasiology 13, 581-608. doi: $10.1080 / 026870399401957$

Black, M., and Byng, S. (1986). Prosodic constraints on lexical access in reading. Cogn. Neuropsychol. 3, 369-409. doi: 10.1080/02643298608252028

Cappa, S. F., Nespor, M., Ielasi, W., and Miozzo, A. (1997). The representation of stress: evidence from an aphasic patient. Cognition 65, 1-13. doi: 10.1016/S0010-0277(97)00024-3

Chiacchio, L., Grossi, D., Stanzione, M., and Trojano, L. (1993). Slowly progressive aplasia associated with surface dyslexia. Cortex 29, 145-152. doi: 10.1016/S00109452(13)80219-5

Coltheart, M., Masterson, J., Byng, S., Prior, M., and Riddoch, J. (1983). Surface dyslexia. Q. J. Exp. Psychol. 35A, 469-495. doi: 10.1080/14640748308402483

Domahs, U., Klein, E., Huber, W., and Domahs, F. (2013). Good, bad and ugly word stress - fMRI evidence for foot structure driven processing of prosodic violations. Brain Lang. 125, 272-282. doi: 10.1016/j.bandl.2013.02.012

Galante, E., Tralli, A., Zuffi, M., and Avanzi, S. (2000). Primary progressive aphasia: a patient with stress assignment impairment in reading aloud. Neurol. Sci. 21, 39-48. doi: 10.1007/s100720070117

Howard, D., and Smith, K. (2002). The effects of lexical stress in aphasic word production. Aphasiology 16, 198-237. doi: 10.1080/02687040143000546

Janssen, U. (2003). Stress assignment in German patients with surface dyslexia. Brain Lang. 87, 114-115. doi: 10.1016/S0093-934X(03)00225-6

Janssen, U., and Domahs, F. (2008). Going on with optimized feet: evidence for the interactions between segmental and metrical structure in phonological encoding from a case of primary progressive aphasia. Aphasiology 22, 1157-1175. doi: $10.1080 / 02687030701820436$ 
Klein, E., Domahs, U., Grande, M., and Domahs, F. (2011). Neuro-cognitive foundations of word stress processing - evidence from fMRI. Behav. Brain Funct. 7, 15-32. doi: 10.1186/1744-9081-7-15

Knecht, S., Dräger, B., Deppe, M., Bobe, L., Lohmann, H., Flöel, A., et al. (2000). Handedness and hemispheric language dominance in healthy humans. Brain 123, 2512-2518. doi: 10.1093/brain/123.12.2512

Laganaro, M., Vacheresse, F., and Frauenfelder, U. H. (2002). Selective impairment of lexical stress assignment in an Italian-speaking aphasic patient. Brain Lang. 81, 601-609. doi: 10.1006/brln.2001.2550

Lloyd, A. J. (1999). Comprehension of prosody in Parkinson's Disease. Cortex 35, 389-402. doi: 10.1016/S0010-9452(08)70807-4

Marshall, J. C., and Newcombe, F. (1973). Patterns of paralexia: a psycholinguistic approach. J. Psycholinguist. Res. 2, 175-198. doi: 10.1007/BF01067101

Miceli, G., and Caramazza, A. (1993). The assignment of word stress in oral reading: evidence from a case of acquired dyslexia. Cogn. Neuropsychol. 10, 273-296. doi: 10.1080/02643299308253465

Rorden, C., and Karnath, H. O. (2004). Using human brain lesions to infer function: a relic from a past era in the fMRI age? Nat. Rev. Neurosci. 5, 813-819. doi: $10.1038 /$ nrn 1521

Rozzini, L., Bianchetti, A., Lussignoli, G., Cappa, S., and Trabucchi, M. (1997). Surface dyslexia in an Italian patient with semantic dementia. Neurocase 3, 307-312. doi: 10.1080/13554799708405014

Van der Hulst, H. (ed.). (1999). Word Prosodic Systems in the Languages of Europe. Empirical Approaches to Language Typology, Vol. 4. Berlin, New York, NY: de Gruyter.

Van Lancker, D. (1980). Cerebral lateralization of pitch cues in the linguistic signal. Papers Linguist. Int. J. Hum. Commun. 13, 201-277. doi: 10.1080/08351818009370498

Van Lancker Sidtis, D., Pachana, N., Cummings, J. L., and Sidtis, J. J. (2006). Dysprosodic speech following basal ganglia insult: toward a conceptual framework for the study of the cerebral representation of prosody. Brain Lang. 97, 135-153. doi: 10.1016/j.bandl.2005.09.001

Wasow, T. (1997). Remarks on grammatical weight. Lang. Variation Change 9, 81-105. doi: 10.1017/S0954394500001800

Wildgruber, D., Ackermann, H., Kreiftels, B., and Ethorfer, T. (2006). Cerebral processing of linguistic and emotional prosody: fMRI studies. Prog. Brain Res. 156, 249-268. doi: 10.1016/S0079-6123(06)56013-3

Wong, P. C. M. (2002). Hemispheric specialization of linguistic pitch patterns. Brain Res. Bull. 59, 83-95. doi: 10.1016/S0361-9230(02)00860-2

Zatorre, R., and Gandour, J. T. (2008). Neural specialization for speech and pitch: moving beyond the dichotomies. Philos. Trans. R. Soc. Biol. 363, 1087-1104. doi: $10.1098 /$ rstb.2007.2161

Conflict of Interest Statement: The authors declare that the research was conducted in the absence of any commercial or financial relationships that could be construed as a potential conflict of interest.

Received: 28 January 2014; accepted: 26 March 2014; published online: 10 April 2014. Citation: Häuser K and Domahs F (2014) Functional lateralization of lexical stress representation: a systematic review of patient data. Front. Psychol. 5:317. doi: 10.3389/ fpsyg.2014.00317

This article was submitted to Language Sciences, a section of the journal Frontiers in Psychology.

Copyright (c) 2014 Häuser and Domahs. This is an open-access article distributed under the terms of the Creative Commons Attribution License (CC BY). The use, distribution or reproduction in other forums is permitted, provided the original author(s) or licensor are credited and that the original publication in this journal is cited, in accordance with accepted academic practice. No use, distribution or reproduction is permitted which does not comply with these terms. 